\title{
COEXISTENCIA DE TRES MODELOS DE INTEGRACIÓN EN ESPAÑA
}

\author{
COEXISTENCE OF THREE INTEGRATION MODEL IN SPAIN
}

\author{
Guillermo Pablo Vansteenberghe Waeterschoot \\ Universidad de Alicante. España/Spain \\ machinesmolles@yahoo.es
}

Recibido/Received: 14/12/2011

Modificado/Modified: 15/03/2012

Aceptado/Accepted: 26/03/2012

\section{RESUMEN}

En este trabajo de investigación se enfatiza el límite que puede llegar a suponer para cualquier país, en este caso España, la existencia de distintas intervenciones modélicas en los diferentes estratos de la administración: Estatal, Regional y Autonómica y a veces incluso Municipal, sobre todo en los inicios de todo proceso de integración de nuevos ciudadanos. Asimismo, se pretende analizar y demostrar la existencia de tres tendencias regionales en los modelos, a pesar de destacar en todos los planes el carácter Intercultural del modelo elegido. Sin embargo, en relación con la realidad socio cultural y política, se deslizan hacía los otros 2 modelos existentes (el Asimilacionista o Francés y el Multicultural o Anglosajón). Con ello la administración se transforma en un límite para la integración.

\section{PALABRAS CLAVES}

Administración, interculturalidad, cohesión social, multiculturalidad, asimilación, etnocentria.

\section{SUMARIO}

1. Introducción. 2. Marco teórico sobre la integración de los inmigrantes: Sus modelos. 3. La administración como posible límite al proceso de integración de las personas extranjeras. 4. Avances en legislación regional en relación con la integración. 5. Conclusión. Bibliografía.

\begin{abstract}
This research paper emphasizes the limits to which one can suppose, for any country -in this case, Spain- the existence of different intervention models at the different layers of administration: state, regional, and provincial, and even at times at the municipal level, especially at the beginning of the whole process of integration of new citizens. Likewise, the existence of three regional tendencies in the models will be analyzed and demonstrated, despite highlighting in all the plans the intercultural character of the chosen model. Nonetheless, concerning the social, cultural, and political reality, the tendency is to slide toward the other two existent models (the Assimilationist, or French; and the Multicultural, or Anglo-Saxon). With that, the administration becomes a limit to integration.
\end{abstract}

\section{KEYWORDS}

Administration, interculturality, social cohesion, multiculturality, assimilation, ethnocentricity.

\section{CONTENTS}

1. Introduction. 2. Theoretical framework of immigrant integration: models. 3. Public administration as a possible limitation in the process of a foreign person's integration. 4. Advances in regional law concerning integration. 5. Conclusions. References. 


\section{INTRODUCCIÓN}

Esta investigación pretende demostrar la existencia de distintas intervenciones modélicas en los diferentes estratos de la Administración: Estatal, Regional (Autonómica) y a veces incluso Municipal. Asimismo, se pretende analizar y demostrar la existencia de tres tendencias regionales en los modelos, a pesar de enfatizarse en todos los planes el carácter Intercultural del modelo elegido. Sin embargo, en relación con la realidad socio cultural y a siempre política, se deslizan hacía el uso de los otros 2 modelos existentes (el Asimilacionista o Francés y el Multicultural o Anglosajón).

La sociedad y su respuesta espontánea también inciden en este particularismo. La presión hacía la limitación de la presencia de inmigrantes en los territorios modelizados termina por repercutir en la política de los partidos. En particular en España implica que en ciertas regiones, determinados partidos defiendan una mayor reducción de esta presencia a través del énfasis que ponen en las políticas de retorno y en una mayor dureza en las leyes que permiten la estancia y el derecho al trabajo; frente a otras donde la presencia es menor y donde la metáfora cultural se siente menos amenazada, presentando una mayor calma institucional que no repercute en los inmigrantes, ya que nos se les vislumbra como posibles agentes de un cambio cultural, al menos no de forma drástica. En estas regiones los mismos partidos defienden políticas de integración positivas destacando los enormes aportes que llevan realizando los inmigrantes.

En España, igual que en el resto de Europa, se sensibiliza más a los inmigrantes que a los autóctonos. Debido a ello, podemos concluir que los inmigrantes se integran mejor que los autóctonos, en una sociedad que cambia ineludiblemente con su llegada, transformándose en más compleja, y donde una gestión de la cohesión social solo puede ser viable en caso de preparar y formar a los viejos ciudadanos a convivir en semejante complejidad socio-cultural.

A continuación expondré cuales son los distintos modelos que definen la metodología de la integración en el mundo occidental. Destacaremos la crisis existente en estos modelos y el cuestionamiento de su eficacia en los propios países creadores de estas intervenciones sociales. Ello no significa que estos modelos no sigan avanzando y consolidándose de forma jurídica y social de manera lenta pero segura, lo que tiende a justificar su base ética y social.

Explicaremos que las personas no tenemos el mismo valor; varios factores así lo ilustran. Los recién llegados, por esa mera condición de noveles, por ser de otro lugar y recién llegados, por ser diferentes, serán concebidos por prolongación, como no aptos. La necesidad de demostrar la valía y utilidad al colectivo general, impera en toda situación de encuentro humano. Finalmente, destacar el enorme impedimento que resulta ser la crisis económica para la correcta aplicación de los planes de integración: (falta de recursos, cambios de prioridades). Dicha circunstancia presenta un panorama de graves consecuencias sociales ya que esta "no acción", implica dos cosas; por un lado, regresión en términos de aceptación de los nuevos ciudadanos por la acción de la crisis, por lo tanto la necesidad frustrada de una mayor intervención por parte de la Administración y, por otro, que este vacío permite que la sociedad reivindique sus soluciones desde la visceralidad más inmediata. Este elemento llevará a la aparición de vías excluyentes en la sociedad de acogida y de reacciones violentas por parte de los nuevos ciudadanos que querrán ser tratados de forma normalizada, a medida que vayan ganando espacio y tiempo, y con ello el deseo de ser tratados como ciudadanos con plenos derechos.

En este trabajo, a la inversa que plantean muchos otros especialistas, queremos defender que la integración no resulta ser el objetivo, por el contrario este solo puede ser una realidad 
social consolidada. Para poder abandonar la etnocentria inicial que solo promueve una sociedad donde todos tienen que cumplir simbologías culturales aceptadas de forma aparentemente mayoritaria, se necesitará de procesos de construcción y de gestión muy diversos. Por tanto se trata de un proceso en construcción donde a menudo la integración no siempre es la óptima, pero es integración al fin al cabo, y a menudo a pesar de las intervenciones bien intencionadas de la Administración.

El objetivo a alcanzar para los gestores de la diversidad, en el término más amplio que permite el acervo cultural humano del momento, es la cohesión social, sobrepasando los únicos límites de la procedencia de los ciudadanos, para adentrarnos en un concepto de sociedad más dinámico, construido sobre las semejanzas y no las diferencias.

\section{MARCO TEÓRICO SOBRE LA INTEGRACIÓN DE LOS INMIGRANTES: SUS MODELOS}

\subsection{Multiculturalidad, asimilación e interculturalidad}

Partimos de una realidad en la que existe una gran confusión terminológica entre los conceptos a tratar, por lo que se hace necesario clarificar previamente en qué consiste cada uno de ellos o a qué definición de las posibles nos adherimos en este contexto.

Siguiendo a Marina (2002) el modelo multicultural y el asimilacionista, junto con el intercultural, son tres posiciones distintas al entender cuál debe ser el mejor modo de gestionar la diversidad cultural en un mismo territorio compartido.

Así, según este autor, la opción que admite la multiculturalidad permite y favorece la organización autónoma de grupos diferentes, de modo que la nación se convierte en un mosaico cultural. Una segunda posibilidad es la que acuña medidas para que los que llegan se asimilen y se adhieran a los modos de hacer y de vivir propios de la sociedad en la que se insertan, perdiendo con ello las señas de identidad de origen y tomando las del nuevo lugar. La tercera posibilidad, la interculturalidad, consiste en la promoción de un intercambio entre todas las culturas que coexisten, favoreciendo el mestizaje, tanto biológico como cultural.

\subsection{A) El modelo multicultural}

Además de José Antonio Marina, es necesario citar otros autores, ya que para comprender el modelo multicultural hemos de diferenciarlo de lo que se entiende por multiculturalidad como simple descripción de la coexistencia de distintas culturas cohabitando en un mismo lugar (Muñoz Sedano, 2001). Otros autores como De Lucas (2002) reconocen la multiculturalidad como la comparecencia de múltiples realidades multiculturales en un mismo espacio de soberanía.

Y, más allá incluso, Carlos Giménez distingue dos planos en la definición: la multiculturalidad, en un plano fáctico, como referencia a la realidad social en la que se da la diversidad cultural, lingüística, religiosa... Y el multiculturalismo, en un plano normativo, como el reconocimiento activo, social e institucional de la diferencia como base de diversos modelos políticos y éticos. Para Giménez, el modelo multicultural es una de las posibles formas de gestionar el pluralismo cultural.

En nuestro caso, adaptado al marco de la inmigración, entenderemos la multiculturalidad como la coexistencia de varias culturas en un mismo espacio geopolítico, y el modelo multicultural como una de las formas de gestionar esta coexistencia desde el 
reconocimiento de las diferencias culturales y la posibilidad de autoorganización, con todas las consecuencias que de ella se derivan.

En la práctica, en el modelo multicultural, pese a nacer de una idea inicial de igualdad de los diferentes, se produce una jerarquización entre los distintos grupos culturales, del mismo modo que se da a nivel individual, ya que este modelo, en cierto modo, transfiere el individualismo propio de algunas sociedades al funcionamiento de las entidades grupales. Algunos de los ejemplos más representativos son los procedentes de las naciones de tradición anglosajona y calvinista, como Inglaterra y Holanda.

Pese al reconocimiento del derecho a la diferencia, en esta jerarquización no todas las culturas están en igualdad de condiciones, ya que algunas se encuentran aisladas y/o segregadas respecto de las otras. Si existe tal jerarquización de culturas, es necesario preguntarse cuáles son los valores de la cultura dominante, ya que éste será el que predominantemente tiña el modo de considerar y gestionar la mejor manera de estructurar el tejido social.

Si intentamos remontarnos a los orígenes de este tipo de sociedades multiculturales, hemos de aterrizar necesariamente en el proceso de descolonización, el cual favorece el retorno de los ingleses hacia la metrópoli, seguidos, en un primer momento, de miembros procedentes de las colonias, los cuales, pese a estar en un nuevo lugar, se ven sometidos a continuar en un sistema cultural injusto.

Tras la II Guerra Mundial, se requería fuerza laboral para reconstruir el país, dando por sentado una pertenencia cultural común basada en el uso del inglés, así como en un ideario común plasmado en la pertenencia a la CommonWealth. Desde entonces, se inicia un modelo de funcionamiento basado en la imposición de los valores "ingleses de Inglaterra" como genuinos y comunes a todos sus habitantes.

En un primer momento, existen quejas que conviven con el resto de la sociedad mediante mínimos contactos, pero estando casi completamente aislados. El colectivo paquistaní es un buen ejemplo de ello, pero también el hindú, jamaicano, subsahariano y asiático.

Es importante dejar claro que el modelo multicultural es una opción, que aunque respeta inicialmente la cultura del otro, le da un valor normalmente inferior al del pueblo de acogida y su simbólica cultural, pese a que el discurso inicial pueda ser el teórico de una coexistencia en igualdad de condiciones.

Esto tiene manifestaciones culturales claras en el estudio de otras culturas distintas a la europea, donde el etnocentrismo es denunciado por múltiples investigadores que acusan tal interpretación reduccionista de sus propias realidades históricas.

El problema se complica cuando nace la segunda y la tercera generación, al considerarse ingleses u holandeses, pero sin cumplir exactamente con los valores culturales dominantes. Además de ser discriminados por la mayoría, estos grupos comienzan también a discriminar a los situados detrás de ellos, transformándose en una discriminación en cadena y de arriba abajo. Así se explica que ser "inglés" pueda representar muy poco para un musulmán, donde dos dimensiones de la identidad cultural de la persona se ven, en muchos casos, confrontadas, y donde muy posiblemente el valor de pertenencia la asamblea de creyentes (UMMA) adquiera un valor superior a la pertenencia a una sociedad construida en mosaico, cuyas piezas son estanco y no se sitúan al mismo nivel.

En Holanda se produce otro factor pernicioso, un valor añadido al del origen y al nivel económico comienza a cobrar importancia: la cantidad. Gran cantidad de holandeses "de segunda clase", sin cumplir las características exactos del grupo dominante, tienen una alta tasa de natalidad, por lo que los holandeses "de primera" temen sufrir una sustitución 
cultural en la cúspide de la pirámide. Su reacción es radicalizar los esquemas culturales aún más y organizarse en torno a respuestas políticas que pregonan la expulsión pura y simple o la asimilación, lo que deja fuera a los creyentes o culturalmente distintos, convertidos en blanco perfecto para la expulsión.

\subsection{B) El modelo asimilacionista}

El modelo asimilacionista es, del mismo modo, un modelo fruto de la colonización, en la que se defendía la idea de brindar al resto del mundo la superioridad cultural la civilización occidental.

Si bien el modelo multicultural parte de la coexistencia y el respeto a la diferencia, por definición, en el modelo asimilacionista la población extranjera (entiéndase también con ello no nacional o de menor arraigo) se ve obligada o inducida a abandonar la posibilidad de mantener su identidad y sus expresiones culturalmente diferentes, de modo que la condición de ciudadano viene dada por pertenecer a un espacio común y adscribirse a las pautas culturales y de funcionamiento de la cultura dominante.

Según Berry (2005), es un modelo de relación en el que la posibilidad que se establece es la de acercarse a la cultura dominante y participar de ella, pero sin tener las mismas posibilidades ni reconocimiento para mantener y/o manifestar la cultura de origen.

En Francia, de tradición revolucionaria, los ciudadanos se ven organizados en torno a la idea y los criterios consecuentes a la adscripción de "ser francés" que suponen laicidad y todos los comportamientos socioculturales aceptados por una tradicional mayoría. Aparentemente más sencillo de gestionar, no deja de ser un modelo de exclusión para grupos que no cumplen estos idearios. De nuevo, se deja de lado el respeto del otro como un igual a pesar de sus diferencias, que en este caso, son religiosas sobre todo.

En este contexto sufren discriminaciones tanto los musulmanes como judíos, ya que, en cierta parte de la sociedad francesa se da un antisemitismo pertinaz, tanto en la derecha como en la izquierda, al participar ambas del simbolismo de ser buen ciudadano al sentirse republicano y laico.

En todo caso, el mantenimiento de la cultura de origen queda relegado al ámbito privado como mal menor, pero desde una falta de reconocimiento social del derecho a la diferencia y su expresión. Los que consiguen adaptarse a esta situación y deslindar sus actividades "diferenciadoras" de la vida social común con la mayoría, pueden alcanzar cierto equilibrio social, sobre todo, si va acompañado de un buen nivel socioeconómico.

Sin embargo, es evidente que estas jerarquizaciones, tanto desde el modelo asimilacionista como desde el multicultural, dejan fuera de la igualdad real de derechos a muchas personas, todos los que no se adecuan a los modos correctos de relacionarse en la sociedad dictados por la mayoría tradicionalmente dominante, con mayor o menor discreción según las sociedades y los modelos imperantes, multicultural y asimilacionista, respectivamente.

\subsection{Hacia una integración real desde la interculturalidad}

La integración está asistiendo, del mismo modo que las anteriores definiciones, a un mal uso generalizado en su significado y a una contradicción entre su significación y su puesta en práctica. Por poner un solo ejemplo de esto último, no hay más que detenerse a ver lo que se entiende por integración en los manuales de la Unión Europea y observar rápidamente cómo su traducción en la práctica no tiene relación alguna con su definición. 
En primer lugar, hemos de entender la integración como una de las posibles formas de gestionar la diversidad cultural, de modo que, siguiendo a García Roca (2002), la integración se entiende como una ideología sociopolítica, un modo de ver el horizonte hacia el que caminar como sociedad; de él se derivaría el modelo integracionista, como el pensamiento conjunto que da forma a esta misma ideología.

En este sentido, la interculturalidad, entendida desde la definición de J.A. Marina, citada más arriba sería la práctica que hiciera posible la realización de la integración, o dicho de otro modo, el medio a promover desde y para un modelo integracionista.

En esta misma línea, y siguiendo a Berry (2005): la integración se entiende como la posibilidad de participar de la cultura a la que se llega al mismo tiempo que participando de y manteniendo la cultura de origen. De este modo, la práctica de la interculturalidad se hace, al igual, imprescindible para conseguir la integración.

Además, la interculturalidad en este contexto es entendida como relación horizontal, enriquecedora y bidireccional, en la que todos los grupos y personas en relación tienen algo que expresar y mostrar a los demás desde su identidad y expresiones culturales, evitando lo excluyente y buscando lo común. Incluso Ramírez Eras, en el paradigma de la interculturalidad, habla de la interculturalidad como proceso de convivencia humana, basado en el respeto a la relación reciproca de valores entre varias culturas.

Sólo desde una promoción abierta de la convivencia entre grupos culturales distintos, más allá del reconocimiento de sus diferencias, será posible una sociedad abierta que vaya más allá de los particularismos creados en torno a la identidad de Estado nación, término que, como hemos ido comentando, está también en plena crisis. Entre otras razones, porque es insoslayable mirar más allá del horizonte de los nacionalismos en un mundo globalizado. Sólo desde una relación horizontal, que dé voz y voto a todas las personas ciudadanas de un territorio será posible evitar la jerarquización entre culturas $\mathrm{y}$, en definitiva, el sometimiento de unas bajo el parecer de las otras.

La integración, así, ha de promoverse a través de prácticas de interculturalidad a través del encuentro entre culturas, el entendimiento mutuo, la observación mutua y un conocimiento mutuo y personalizado cada vez mayor.

Así entendido, este encuentro intercultural promueve la armonización de las relaciones humanas y, por tanto, promueve, como sociedad y como grupo humano, una evolución. De hecho, desde los mismos países del Sur de Europa se defiende la interculturalidad como una reflexión científica armonizante. El discurso se orienta desde un "pensamiento intercultural" y se propone una "hermenéutica intercultural", donde, en función de la calidad del encuentro se forje la autorreflexión, la propia identidad, siempre en dinamismo y cambio, y el respeto al otro.

Lo genuino de la interculturalidad es la creación de una situación nueva, modificando y redefiniendo las situaciones multiculturales, no sólo porque se puedan unir más culturas a una particular situación multicultural (pluralismo democrático):, sino también porque la comunicación y el encuentro entre culturas favorece el surgimiento de nuevas formas culturales, resultado de las nuevas necesidades y formas de identificación grupal y social, de nuevo, desde la horizontalidad, la aceptación de las diferencias como compatibles, y el énfasis en lo común y compartido.

Así, debemos priorizar en el encuentro intercultural las historias personales compartidas. Y sobre esta base sólida de sociabilidad de intereses y conocimiento en nuestros encuentros, siempre apoyándonos en las aportaciones de cada parte, podremos interrogarnos sobre lo que nos es posible construir juntos. 
Podremos entender, entonces, la práctica del encuentro, no sólo como un proceso de educación (en): intercultural (idad): sino como lugar y proceso donde la terminología de la interculturalidad no es sino la herramienta que posibilita un producto común (hecho por todos): para un mundo mejor.

Para ver esta posibilidad como una alternativa realista, lejos de la utopía inalcanzable, hemos de tener muy presente que el mestizaje fue y es la forma de encuentro entre culturas, siempre y cuando se entienda como enriquecimiento, mediación y horizontalidad, y no como subordinación y renuncia, huyendo del esquema de la absorción de lo dominado.

Sabemos bien que el encuentro entre culturas no es nuevo, y ha producido síntesis culturales que se evidencian en estrategias sociopolíticas y mecanismos de convivencia, así como en producciones estéticas como la música, los ritos, las fiestas populares, las danzas, el arte, y la literatura de cualquier lugar, empezando por nuestro contexto "español", tanto a lo largo de su historia como en su momento presente.

Pero no solamente se establece una relación con los otros, sino que se inicia un viaje comprensivo, que es más que ese flujo no estructurado de objetos, imágenes, relatos, signos, información, costumbres, etc., de los "massmedia" para darle un significado, un sentido al mundo del otro, en una actitud de aceptación empática. En definitiva, como dice Carl Rogers, es hablar de la capacidad de percibir el marco de referencia de la otra persona, con los significados y componentes emocionales que contiene, en un esfuerzo para poder ponerse en el lugar del otro desde su propia mirada.

Y, más allá de todas estas dimensiones y matices, el eje central de cualquier avance hacia la ciudadanía intercultural es la noción de una igualdad de derechos y deberes básicos para todos los ciudadanos de cualquier territorio y en cualquier situación administrativa. En este sentido, empezamos a ver lo mucho que nos queda, a todos, aún por hacer.

\subsection{LA ADMINISTRACIÓN COMO POSIBLE LÍMITE AL PROCESO DE INTEGRACIÓN DE LAS PERSONAS EXTRANJERAS}

\subsection{La Administración española: distribución}

Resulta paradójico destacar la intervención humana que por definición está destinada a gestionar y resolver los asuntos que atañen a la sociedad en su totalidad y al individuo en particular, como un límite a la integración de nuevos grupos humanos que por motivos diversos pretenden integrar de forma normalizada el funcionamiento normativo de la nueva sociedad a la cual quieren pertenecer.

La falta de experiencia y la novedad del flujo que impidió la mera copia de modelos llevados adelante anteriormente en países con más experiencia, es una de las piedras angulares para afirmar que era evidente que la administración iba a transformase en un límite, que no pretendemos eterno ni voluntario, al menos no en todos los casos.

Tras la más importante, la inexperiencia, aparecen otras razones que confirman la afirmación defendida: España está administrativamente dividida en tres escalones administrativos: $1^{\circ}$ El Nacional, $2^{\circ}$ el Regional, $3^{\circ}$ El Municipal.

La falta de una definición clara de Estado y su reflejo evidente en la inoperancia del Senado y la imposibilidad real de su reforma, además de la lucha constante entre el concepto de Estado periférico y la otra definición Centralista hacen muy difícil una buena 
relación entre los distintos estamentos administrativos del Estado y por ello produce una ruptura relativa entre estos por inconexión, no siempre de forma uniforme en todos los lugares de España, sobre todo entre el regional y el municipal, a la hora de tratar el fenómeno migratorio y sobre la integración de los nuevos ciudadanos.

\subsection{La administración del Estado: sus límites en términos de integración}

El Estado se reserva las prerrogativas de control de Fronteras y la creación de legislación con respecto a la permanencia, la facultad de trabajo y la entrada en España de los extranjeros, dejando a las regiones la facultad, nada baladí, de inventar los entramados y arquitecturas para facilitar la integración real de los individuos, situación que en último término, se escenifica aún mejor en el municipio. Este nivel, casi totalmente olvidado en la elaboración de planes y de modelos de integración en las primeras fases del proceso integrador, es clave en el proceso de integración social, sin embargo, a hora de la verdad se encuentra solo y dejado de lado en la elaboración de las políticas de integración.

Considerando este factor, podemos observar que esta desconexión y el monopolio de ciertas funciones en los distintos estamentos, solo puede redundar en dificultades para la puesta en marcha de un modelo español, aceptado por todos y con un cierto viso o intención de servir para ese Estado en su conjunto.

El modelo Español se define como intercultural, término ya ampliamente definido en este trabajo, y que veremos que aunque voluntarioso en su deseo, es prácticamente imposible de aplicar a nivel estatal y a nivel regional (Comunidades Autónomas), y desde luego, los impedimentos para su buena aplicación van a permitir la aparición de los otros dos modelos asimilacionista y multicultural), produciendo coexistencia de los tres modelos en el territorio nacional, $\mathrm{y}$ a veces a la vez en las mismas regiones.

El Estado español carece de competencias efectivas para ordenar e imponer un modelo a las Comunidades Autónomas, que tiran de su modelo cultural y social propio, y definido muy a menudo por el partido político que dirige cada Comunidad (región) para elaborar un modelo de integración que definiremos en las primeras etapas como posibilista y favorecedor del respeto a la diferencia en su forma. Todos los modelos apuestan por el desarrollo de las asociaciones de inmigrantes como interlocutores del nuevo colectivo, con ello ya siembran las semillas de un modelo multicultural, ya que todos los colectivos irán distribuyéndose, en relación con la ayuda pública, en función de su origen y en torno a sus credos más frecuentes, facilitando así la creación de una ruptura de la uniformidad de necesidades que tiene este colectivo, promoviendo con ello el sistema de islas culturales. Si a esto sumamos la ignorancia de la sociedad de acogida a la hora de entender a los recién llegados, su desinterés en el proceso de integración que entiende como exclusivo al colectivo inmigrante y la imposibilidad de la administración de plantearse la necesidad de sensibilizar a las dos parte implicadas por igual, partiendo de una etnocentria lógica, tenemos la sombra de un modelo asimilacionista.

Además, con el estímulo de la integración a través de las asociaciones la Administración favorece la creación de un escalón nuevo en la atención social, un grupo micronizado en una mirada de asociaciones definidas por el origen. (Modelo Multicultural).

\subsection{Administración regional: tres visiones}

Al no crecer las propuestas del Estado a nivel de integración teórica, las autonomías fueron adelantándose a éste creando sus formas de interpretar el modelo intercultural hasta 
crear tres submodelos que responden a las idiosincrasias culturales representadas en el territorio español.

\section{3.a) Modelo intercultural-asimilacionista: regiones con núcleo cultural marcado}

Los modelos que se ajustan a una realidad más autonomista son: el modelo Catalán, el modelo Vasco, el modelo Gallego, este último con una tendencia diferenciada de los otros dos, dependiendo de la alternancia política entre nacionalistas gallegos y representantes de los dos partidos mayoritarios a escala nacional. Este modelo, necesitado de una reafirmación más autonomista y partiendo de que su realidad cultural requiere de una especial defensa de la misma por considerarla en peligro de extinción, plantea la inclusión de los inmigrantes a hacia la obligatoriedad del aprendizaje de la cultura autonómica a través del conocimiento obligatorio del idioma vernáculo, claro reflejo de la imposición de un modelo asimilacionista basado en la defensa de la cultura autóctona, paradigma de este modelo. En Cataluña las advertencias de los políticos más nacionalistas, primero desde la oposición y después desde el gobierno autónomo, advirtiendo que la integración de los inmigrantes representaban un reto ineludible para la salvaguardia de la cultura autóctona, define claramente la necesidad de asimilar la cultura catalana como elemento indiscutible de integración. Artur Más, (Presidente del Gobierno catalán) invita a los inmigrantes a participar del "sueño Catalán" abrazando la catalanidad, pero lo hace también mediante la imposición de un sistema de puntos para juzgar el nivel de integración de una persona y beneficiarse o no de las ayudas oficiales. Esta circunstancia nos permite situarnos en dos realidades: primero, afirmar que ante el miedo constante de la osmosis cultural contemplado como pérdida, la lógica del uso de herramientas de inserción obligatoria en la sociedad de acogida es una realidad concebida para proteger a los autóctonos, y, segundo el objetivo a alcanzar ineludiblemente para los inmigrantes es justamente aceptar la cultura catalana como su nueva cultura. Los aprendizajes culturales y la emancipación cultural a través del buen conocimiento de la cultura de recepción pocas veces serán contemplados como voluntarios. Está claro que esta situación no puede por menos que producir una nueva discriminación grupal, con su seno en la Administración y en un Plan de Integración, llamado a sostenerse teóricamente sobre la bidireccionalidad y la interculturalidad, siendo evidentemente imposible a tenor de las circunstancias planteadas.

\section{3.b) Modelo intercultural: regiones con un núcleo cultural normalizado}

Otro modelo regional se extiende sobre regiones que no atesoran la sensación de estar en peligro a nivel cultural y que solo experimentan los cambios normales de recepción de nuevas simbologías aceptándolas o no, y que tienden a estar más cerca de la interculturalidad como puede ser el Andaluz.

En este trabajo no se afirma que en estas regiones no aparezcan los mismos problemas de desconexión entre las distintas administraciones, así como una aproximación al hecho migratorio diferente a otras regiones, por parte de la población y de las instituciones; solo se observa una menor presión cultural por parte de la sociedad de acogida sobre los nuevos ciudadanos. Esto se justifica en parte por la no existencia de una segunda lengua y una cierta cercanía al ser español, circunstancia esta que disminuye considerablemente los importantes esfuerzos añadidos en las otras regiones anteriormente analizadas. Esto repercute en la menor presencia de un modelo asimilacionista de corte regional, que se superponga, como en las otras autonomías, a la asimilación promovida por el Estado. La llegada de inmigrantes del Magreb a Andalucía ha generado interés en ciertos sectores de 
la sociedad andaluza por recuperar la historia en común, este hecho es una buena muestra de cómo en este modelo cultural los nuevos ciudadanos tienen mejores oportunidades para ejercer su integración en la nueva sociedad de acogida.

\section{3.c) Modelo intercultural: regiones bilingües}

Finalmente, una serie de Comunidades Autónomas utilizan su tradición de bilingüismo para pretender que el aprendizaje de la lengua se transforme en una ganancia social para las personas inmigrantes que pretender vivir en sus territorios, sin obviar los problemas de rechazo cultural que siguen existiendo como en las otras dos opciones. También es el caso de la Comunidad Valenciana, que se define como intercultural, y entiende que el proceso de aprendizaje debe ser consentido y bidireccional. Al margen de que todas las regiones autonómicas sufren la dificultad de la construcción de la bidireccionalidad, desde premisas de integración propuestas por la sociedad autóctona; la diferencia de la Comunidad valenciana con aquellas Comunidades, definidas en este trabajo como "de núcleo cultural marcado" es que ésta defiende su identidad cultural, para ser más justos bi-cultural, de una forma diferente a las regiones del primer grupo, en este caso no imponiendo el idioma valenciano sobre el castellano, ni promoviendo cuál es culturalmente el más importante para que la cultura valenciana quede claramente dibujada. Eso es al menos lo que defienden las autoridades políticas que rigen la administración valenciana en estos momentos. Para los inmigrantes este hecho repercute en que el aprendizaje idiomático es una opción y no una imposición; Valenciano y Castellano, (lo más común ambos) y de forma voluntaria. Así la sociedad de recepción valora de manera muy positiva al que elige, sin obligación de que este esté obligado a conocer la cultura que le rodea, alejando en parte el miedo a la sustitución cultural autóctona, al tiempo que evitando la presión asimilacionista sobre los hombros de los inmigrantes.

Esto no significa que para evitar esta presión, que aunque menor existe, no tengamos que trabajar sobre los dos colectivos, para que tanto unos como otros se acepten como iguales con sus diferencias. Está claro que esta opción facilita la posibilidad del acercamiento mutuo al evitar, con la imposición de los criterios culturales de una parte sobre la otra, el rechazo de la cultura de recepción por parte de los individuos, a veces colectivos enteros, por temor a perder la suya.

\subsection{Avances en legislación regional en relación con la integración}

Con la nueva Ley de Extranjería, y de su Reglamento recientemente publicado, asistimos a una importante evolución respecto de la transferencia de poder que se genera por parte del Estado hacía las autonomías, hecho éste que va a cambiar el reparto de prioridades en este nivel de gestión. La nueva Ley incluye la posibilidad de que las Autonomías puedan empezar a gestionar la residencia y los permisos de trabajos en un futuro cercano. Ello significa un crecimiento del aspecto de control de fronteras que comienza a repercutir sobre las Comunidades Autónomas que pasan, de meras integradoras de personas a gestoras de la legalidad, en términos de presencia en el país por parte de los extranjeros. La primera en postularse ha sido Cataluña con la coherencia de sentirse Estado dentro de un Estado, ahondando si cabe aún más en la diferencia de modelos de integración ya mencionada con el resto de regiones. Por otro lado, las Regiones se están dotando o piensan dotarse de Leyes de Integración, organizando así un espacio jurídico que hasta el momento dependía de la Administración estatal; la Comunitat Valenciana encabeza dicha iniciativa. Ante la lentitud y la inconexión de las partes, estas regiones han decidido regular todo lo relacionado con la 
integración social de los inmigrantes, en el caso de la Comunitat Valenciana de forma modélica, basándose en un modelo Intercultural tipo. Cuando otras regiones se decidan a crear estos espacios jurídicos propios, tal vez sea necesario abordar cambios que podrían variar algo el fondo, pero no la forma, añadiendo a la diversidad de intervenciones modélicas otro elemento que viene a confirmar la premisa de este trabajo: la inconexión entre las administraciones en tema de inmigración favorece una gestión excesivamente diversificada, hecho que facilita una clara dificultad de integración para los inmigrantes a nivel Estatal y también a nivel regional, en caso de trasladarse a otra Comunidad Autónoma. Se confirma así a la Administración como un límite real a la integración.

\subsection{Varios tipos de extranjeros}

Analicemos otro límite institucional más: la perspectiva en dos clases de extranjeros. La primera, la está construyendo el Estado español desde dentro y desde una percepción subjetiva anclada en dos tipos de inmigración: el de índole laboral y el relativo al ocio. La segundo, impuesta desde fuera por las instituciones europeas, que han exigido la división entre comunitarios y no comunitarios. Esto por definición determina la existencia de un modelo multicultural en árbol donde la procedencia es un elemento fundamental para poder ocupar un puesto $u$ otro en este árbol social.

Al crear una jurisprudencia particular con reglas especificas para los extranjeros, se echa por tierra la bidireccionalidad, pero también se atenta contra la igualdad recogida en nuestra Constitución, e incluso se contribuye claramente a diversificar el modelo multicultural. La gran profusión de Leyes de extranjería que han ido apareciendo en los últimos 20 años ha producido una motorización legal de nefastas consecuencias. El exceso de jurisprudencia, que si bien en muchos casos puede ser complementario, en otros, es claramente opuesta a lo anterior, circunstancia que ha producido una cierta indefensión en el colectivo migrante, debido al constante reciclado de los funcionarios dedicados a los temas de extranjería, que no dan abasto a la hora de imbuirse de la profusa legislación. Por otro lado, determina la dificultad de los propios inmigrantes para controlar sus derechos y sus obligaciones, sometidas ambas a constantes cambios. Ambas circunstancias han facilitado la creación de distintos grupos en función de las Leyes que se les aplica para su regulación administrativa, gozando los primeros de más facilidades y los últimos de más dificultades, una nueva forma de dividir, de fraccionar los colectivos de inmigrantes. En definitiva, es la consagración por parte de la Administración de un modelo multicultural que otorga o no réditos en función del origen del ciudadano extranjero, incidiendo así de forma directa en la visualización de los extranjeros por parte de la sociedad autóctona como distintos grupos, con diferente valor de reconocimiento.

Este aspecto cobra toda su gravedad a través de una legislación específica para extranjeros en el área laboral, que diferencia a autóctonos de extranjeros, en función de la obligación o no de cotizar de unos y de otros en el sistema laboral, en el caso de los segundos como requisito imprescindible para poder seguir gozando del privilegio de residir y trabajar en nuestro país. De nuevo, a través de la Administración se escenifica la capacidad de dividir a la población y alejarla del escenario idóneo de la cohesión social y de dificultar con ello la integración en un modelo definido como intercultural. Esta diferencia, es una de las más determinantes entre autóctonos y foráneos y que de nuevo viene a incidir en la existencia de un modelo multicultural donde los españoles tienen todas las ventajas de partida y los extranjeros se las distribuyen por tramos de tiempo de permanencia hasta escapar y entrar en la normalidad institucional. 


\section{CONCLUSIÓN}

En este punto llegamos a una conclusión de repercusiones graves y aparentemente inevitables con las premisas culturales que sostienen los paradigmas de nuestra sociedad: los que deben adaptarse son los inmigrantes, los de la sociedad de acogida ya están correctamente situados. Este es la base del fracaso de los modelos utilizados como herramientas de integración en los países del norte de Europa. Las sociedades han cambiado y los extranjeros se adaptan mejor que los autóctonos ya que estos no aprenden a moverse en los nuevos parámetros cada vez más complejos de una sociedad con presencia de simbologías muy diversas, de religiones prácticamente inexistentes anteriormente; sin embargo, las circunstancias señaladas han provocado una huida hacia el exterior de las ciudades, guetizando con ello de forma involuntaria a los recién llegados, al tiempo que creando una nueva generación, a través de los hijos, que ya no son los otros, o al menos no lo quieren ser. Precisamente los modelos que han desarrollado estos escenarios de ruptura han sido el asimilacionista francés y el multicultural anglo-sajón, ambos dados ya por fracasados por sus propios creadores.

Ello no significa que ambos modelos sigan funcionando, incluso legalmente, produciendo directivas y líneas de trabajo para intentar una cohesión social considerada imposible con estos modelos de integración. Pero tampoco están siendo sustituidos por otro u otros más acordes a la consecución de una cohesión social coherente con los retos de una sociedad compleja. Por su parte, el modelo Intercultural está siendo aplicado solo en parte. Su desarrollo es muy difícil porque los autóctonos han decidido que no hay nada que cambiar, en muchos casos como hemos visto, incluso generando resistencias para que no se mueva, frente a la presión del inevitable mestizaje.

La inercia de la población de acogida ha producido un extraño resultado de integración, donde finalmente se han dado cuenta de que los hijos y nietos se han integrado con relativamente buena intensidad en la sociedad de recepción, ya que muchos de ellos ya la consideran como suya, y lo han hecho de manera magnifica y con una preparación que supera la de muchos autóctonos al haber sumado habilidades culturales. A pesar de ello, la sensación final es que existen muchos ciudadanos que anidan un sentimiento de frustración basado en la falta de esfuerzo de adaptación a las nuevas realidades sociales, llegando al convencimiento de que en todo este proceso, desgraciadamente, solo han perdido espacio.

\section{BIBLIOGRAFÍA}

BERRY, J.W. (2005), "Fundamental psychological processes in intercultural relations", en Landis, D. y Bennett, J. (eds.), Handbook of intercultural research. Thousand Oaks: Sage, pp.166-184.

CORTINA, A. (2007), Ética de la razón cordial, Educar en la Ciudadanía en el Siglo XXI. Oviedo: Nobel.

DE LUCAS, J. y TORRES, F. (2002), Inmigrantes: ¿Cómo los tenemos? Madrid: Talasa.

ELIADE, M, (1983), Die Sehnsucht yacht dem Ursprung. Frankfurt am Main: H.Derr.

GARCÍA ROCA, J. (2002), Multiculturalidad e inmigraciones, en El discurso intercultural. Madrid: Biblioteca Nueva.

HEIDEGGER, M. (1960), Unterwegs zur Sprache, Pfullingen, 86

HÖFFE, O. (2000), Derecho intercultural. Barcelona: Gedisa.

MALL, R. A. (2000), “The concept of an Intercultural Philosophy”, Revista electrónica Polylog. 
INTERNATIONAL LABOUR ORGANIZATION (ILO), ORGANIZACIÓN MUNDIAL DEL TRABAJO (OIT). (2006), Global Employment Trends, Brief, International Labour Office, Geneva.

LEY ORGÁNICA 7/1985, de 1 de julio, "Sobre derechos y libertades de los extranjeros en España y su integración social", BOE, n 158 de 3/7/1985, pp. 20824 a 20829.

LEY ORGÁNICA 4/2000, de 11 de enero, "Sobre derechos y libertades de los extranjeros en España y su integración social" $B O E \mathrm{n}^{\mathrm{o}} 10$, de 12 de enero, pp. 1139 a 1150.

LEY ORGÁNICA 8/2000, de 22 de diciembre, $B O E \mathrm{n}^{\circ} 307$, de 23 de diciembre, pp. 45504 a 45502.

LEY ORGÁNICA $11 / 2003$, de 29 de septiembre de medidas concretas en materia de seguridad ciudadana, violencia doméstica e integración social de los extranjeros, $B O E \mathrm{n}^{\mathrm{o}} 234$, de 30 de septiembre, pp. 35398 a 35404.

LEY ORGÁNICA 14/2003, de 20 de noviembre, $B O E \mathrm{n}^{\circ}$ 279, de 21 de noviembre, pp. 41193 a 41204.

LEY ORGÁNICA 14/2009, de 11 de diciembre, $B O E \mathrm{n}^{\circ}$ 299, de 12 de diciembre, pp. 104986 a 105031. MARINA, J.A. (2002), La Selva del Lenguaje, Madrid

MUÑOZ SEDANO, A. (2001), "Hacia una Educación Intercultural: Enfoques y modelos", Encounters on Education, Universidad Complutense y Universidad de Manitota-Canadá, 1, pp. 81-106.

PLAN DIRECTOR DE INMIGRACIÓN Y CONVIVENCIA 2008-2009, Conselleria de Solidaridad y Ciudadanía, Comunidad Valenciana

II PLAN INTEGRAL PARA LA INMIGRACIÓN EN ANDALUCÍA 2006-2009, Consejería de Gobernación, Junta de Andalucía

III PLAN INTEGRAL PARA LA INMIGRACIÓN EN ANDALUCÍA 2009-2012, Conserjería de Gobernación, Junta de Andalucía

PLAN DE INTEGRACIÓN DE LA COMUNIDAD DE MADRID 2009-2012, Consejería de Inmigración y Cooperación, Comunidad de Madrid

PLAN DE CIUDADANÍA E INMIGRACIÓN 2009- 2012, Generalitat de Catalunya

PLAN NACIONAL ESTRATÉGICO DE CUIDADANÍA E INTEGRACIÓN 2007-2010. Ministerio de Trabajo y Migración.

SOCIAL SCIENCES RESEARCH COUNCIL (1954), "Acculturation: An Exploratory Formulation" American Anthropologist, 56, pp. 973-1002.

SOPEMI (2007), Perspectivas de las Migraciones Internacionales, edición OBCD

VANSTEENBERGHE, G.P. (2011), Los Límites para la Integración de los Inmigrantes en España. Valencia: Trabajo de Investigación, Universidad de Valencia. Departamento de Filosofía Moral.

VANSTEENBERGHE, G.P. (2010): “Convivencia Social y Gestión de la Diversidad. La Integración y sus Límites" en El Desafío de la Inmigración, pp. 137-170, Capítulo Español del Club de Roma,Valencia.

\section{Breve currículo:}

\section{Guillermo Pablo Vansteenberghe Waeterschoot}

Licenciado en Filosofía y Letras Universidad de Valencia, Profesor Honorífico de la Universidad de Alicante, doctorando en la Universidad de Valencia y especialista en Inmigración. Ex-Director General de Inmigración de la Comunidad Valencia; Ex-Gerente de la Fundación CeiMigra y Co-coordinador del Capítulo Valenciano del Club de Roma. Traductor científico, articulista y ponente en temas de Inmigración; Miembro de la UNESCO, Valencia, coordinador del primer Plan Valenciano de Integración. Colaborador en diversos Másteres en Políticas de Integración, Inmigración, Codesarrollo. Últimos trabajos: Los Límites para la Integración de los Inmigrantes en España, Departamento de Filosofia Moral, Universidad de Valencia, 2011; Convivencia Social y Gestión de la Diversidad. La Integración y sus Límites. El Desafío de la Inmigración, pp. 137-170, Club de Roma, 2011. El Aula como herramienta de Cohesión Social, El Desafío de la Inmigración. Argumentario. Mesa redonda, Club de Roma, 2011; “Educación e Inmigración”, Revista Contraste, 2010, Valencia. 